\title{
Doses de AIB no enraizamento de estacas de maracujá
}

\author{
AIB doses in rooting of passion fruit cuttings \\ Dosis de AIB en el enraizamiento de esquejes de maracuyá
}

Recebido: 22/02/2021 | Revisado: 03/03/2021 | Aceito: 05/03/2021 | Publicado: 14/03/2021

Leandro Cardoso De Lima

ORCID: https://orcid.org/0000-0003-3195-3691 Instituto Federal de Educação, Ciência e Tecnologia Goiano, Brasil E-mail: leandrolima.14@outlook.com

Luís Sérgio Rodrigues Vale

ORCID: https://orcid.org/0000-0002-6303-9063 Instituto Federal de Educação, Ciência e Tecnologia Goiano, Brasil E-mail: luis.sergio@ifgoiano.edu.br

Dennis Ricardo Cabral Cruz

ORCID: https://orcid.org/0000-0002-5209-7751 Universidade Federal de Goiás, Brasil E-mail: denisribral@gmail.com Juliano Silva Queiroz

ORCID: https://orcid.org/0000-0001-7683-3285 Instituto Federal de Educação, Ciência e Tecnologia Goiano, Brasil

E-mail: julianoagronomia260@ hotmail.com

Rannie do Carmo Souza

ORCID: https://orcid.org/0000-0002-6462-9209 Instituto Federal de Educação, Ciência e Tecnologia Goiano, Brasil E-mail: ranniesouza@hotmail.com

Maurício Deçones Alves Araújo

ORCID: https://orcid.org/0000-0002-2021-1222 Instituto Federal de Educação, Ciência e Tecnologia Goiano, Brasil E-mail: mauricio.decones@hotmail.com

Cássio da Silva Kran

ORCID: https://orcid.org/0000-0001-5084-5034 Instituto Federal de Educação, Ciência e Tecnologia Goiano, Brasil E-mail: cassiosilvakran@gmail.com

\begin{abstract}
Resumo
A produção de maracujá no Brasil é focada principalmente na produção de maracujá azedo, por atrair maior interesse por parte dos consumidores. A propagação desta espécie é feita majoritariamente por meio de sementes, mas também pode ser realizada por propagação vegetativa. Objetivou-se avaliar o enraizamento de estacas de maracujá azedo com aplicação de AIB em diferentes concentrações e dois tipos de estacas (com e sem folhas). As estacas utilizadas foram coletadas em Uruana-GO e possuíam duas gemas. Utilizou-se delineamento em blocos casualizados em arranjo fatorial 2 x 4 (estacas com e sem folhas; quatro concentrações de AIB: 0, 1.000, 2.000 e $4.000 \mathrm{mg} \mathrm{L}^{-1}$ ), com cinco repetições e cinco estacas por unidade experimental. As estacas tratadas foram estabelecidas em canteiro com areia, na câmara estufim. A avaliação das estacas foi aos 40 dias após o plantio. As variáveis utilizadas foram as estacas: vivas, mortas, enraizadas, com calos e número de brotos. Os tratamentos de AIB na menor dose (zero) e na maior dose $\left(4.000 \mathrm{mg} \mathrm{L}^{-1}\right)$ proporcionaram maiores porcentagens de estacas vivas, com calos e número de brotos. Houve decréscimo no enraizamento de estacas com o aumento das doses de AIB. O aumento das doses de AIB até $2.000 \mathrm{mg} \mathrm{L}^{-1}$ proporcionou maior mortalidade de estacas. A presença de folhas nas estacas produziu maior porcentagem de estacas vivas, enraizadas, com calos e brotos. O tratamento mais indicado é a não aplicação de AIB e a utilização de estacas com folhas.
\end{abstract}

Palavras-chave: Estaquia; Maracujá azedo; Propagação; Regulador de crescimento.

\begin{abstract}
The production of passion fruit in Brazil is mainly focused on the production of sour passion fruit, as it attracts greater interest on the part of consumers. The propagation of this species is done mainly through seeds, but it can also be carried out by vegetative propagation. The objective was to evaluate the rooting of sour passion fruit cuttings with application of IBA in different concentrations and two types of cuttings (with and without leaves). The cuttings used were collected in Uruana-GO and had two buds. A randomized block design was used in a 2 x 4 factorial arrangement (cuttings with and without leaves; four concentrations of IBA: 0, 1,000, 2,000 and 4,000 $\mathrm{mg} \mathrm{L}^{-1}$ ), with five replicates and five cuttings per experimental unit. The treated cuttings were established in a sand bed, in the greenhouse. The cuttings were evaluated 40 days after planting. The variables used were the cuttings: live, dead,
\end{abstract}


rooted, with calluses and number of shoots. The treatments of IBA in the lowest dose (zero) and in the highest dose $\left(4,000 \mathrm{mg} \mathrm{L}^{-1}\right)$ provided higher percentages of live cuttings, with corns and number of shoots. There was a decrease in cuttings rooting with the increase in IBA doses. The increase in IBA doses up to $2,000 \mathrm{mg} \mathrm{L}^{-1}$ provided higher cuttings mortality. The presence of leaves in the cuttings produced a higher percentage of live cuttings, rooted, with calluses and shoots. Leafless cuttings produced more dead cuttings. The most suitable treatment is the nonapplication of IBA and the use of cuttings with leaves.

Keywords: Cuttings; Sour passion fruit; Propagation; Growth regulator.

\section{Resumen}

La producción de maracuyá en Brasil se centra principalmente en la producción de maracuyá ácida, ya que atrae mayor interés por parte de los consumidores. La propagación de esta especie se realiza principalmente a través de semillas, pero también se puede realizar mediante propagación vegetativa. El objetivo fue evaluar el enraizamiento de esquejes de maracuyá ácida con aplicación de IBA en diferentes concentraciones y dos tipos de esquejes (con y sin hojas). Los esquejes utilizados se recolectaron en Uruana-GO y tenían dos yemas. Se utilizó un diseño de bloques al azar en un arreglo factorial de 2 x 4 (esquejes con y sin hojas; cuatro concentraciones de IBA: 0, 1,000, 2,000 y 4,000 $\mathrm{mg} \mathrm{L}^{-1}$ ), con cinco repeticiones y cinco esquejes por unidad experimental. Los esquejes tratados se establecieron en un lecho de arena, en invernadero. Los esquejes se evaluaron 40 días después de la siembra. Las variables utilizadas fueron los esquejes: vivo, muerto, enraizado, con callos y número de brotes. Los tratamientos de IBA en la dosis más baja (cero) y en la dosis más alta $\left(4.000 \mathrm{mg} \mathrm{L}^{-1}\right)$ proporcionaron mayores porcentajes de esquejes vivos, con callos y número de brotes. Hubo una disminución en el enraizamiento de los esquejes con el aumento de las dosis de IBA. El aumento de las dosis de IBA hasta $2.000 \mathrm{mg} \mathrm{L}^{-1}$ proporcionó una mayor mortalidad de las estacas. La presencia de hojas en los esquejes produjo un mayor porcentaje de esquejes vivos, enraizados, con callos y brotes. Los esquejes sin hojas produjeron más esquejes muertos. El tratamiento más adecuado es la no aplicación de IBA y el uso de esquejes con hojas.

Palabras clave: Esquejes; Maracuyá ácida; Propagación; Regulador de crecimiento.

\section{Introdução}

O gênero Passiflora é de grande expressividade, com cerca 400 espécies espalhadas pelo mundo e desse total, 120 espécies no Brasil, que é o país com maior número de espécies nativas (Santos et al., 2012). O maracujazeiro é uma frutífera muito cultivada e apreciada sob diversas formas nas mais variadas regiões do Brasil (São José et al., 2011). O Brasil ocupa o posto de principal produtor a nível mundial, sendo responsável pela produção de 593.429 t em 2019, abrangendo todos os estados brasileiros e DF, com a maior produção concentrada na região Nordeste (Embrapa, 2020).

O maracujazeiro proporciona uma ótima alternativa de cultivo entre as frutíferas, por oferecer rápido retorno econômico e receita distribuída durante o ano todo (Meletti, 2011; Ferreira et al., 2020). O principal foco dos estudos acadêmicos sobre a cultura do maracujazeiro é dirigido à espécie Passiflora edulis devido à elevada demanda comercial (Vale et al., 2020).

A grande maioria dos produtores utiliza a propagação sexuada, por meio de sementes para a produção de mudas de maracujá, mas outra alternativa viável é a produção por via vegetativa, mediante o enraizamento de estacas (Meletti, 2002). A estaquia é um método de propagação assexuada que consiste na retirada de ramos das plantas de maracujazeiro, com 2 ou 3 gemas, que são colocadas para enraizar e originar plantas geneticamente idênticas às plantas-matrizes (Junghans et al., 2016). A propagação de plantas através da estaquia, permite vantagens como conservar as características genéticas desejáveis da planta, produção mais rápida e em maior escala de mudas a partir de uma única planta (Hartmann et al., 2011)

Diante da alta incidência de doenças na nossa região, se faz necessário o uso dessas técnicas, que por sua vez pode ser realizada em conjunto com a indução hormonal permitindo o melhor enraizamento. Reguladores de crescimento à base de auxina como o ácido indolbutírico (AIB), ácido naftalenoacético (ANA) e ácido indolacético (AIA) são os exemplos mais comuns empregados atualmente no processo de propagação de plantas por estacas (Lima Neto et al., 2009; Vale et al, 2020). O AIB apresenta como vantagens a baixa toxicidade, ação mais localizada do que outros produtos e maior estabilidade química no corpo da estaca (Bernardo et al., 2011).

O processo de seleção de plantas matrizes superiores, que possuam características consideradas altamente desejáveis, 
aliada a propagação e multiplicação por estacas, pode contribuir para a obtenção de lavouras superiores às atuais. Portanto, se faz interessante o desenvolvimento de estudos que avaliem melhor a propagação vegetativa por estacas, bem como a dosagem adequada de regulador de crescimento AIB para Passiflora edulis. O objetivo do presente trabalho foi avaliar o enraizamento de estacas de maracujá azedo com aplicação de ácido indolbutírico em diferentes concentrações e dois tipos diferentes de estacas, com e sem folhas.

\section{Metodologia}

$\mathrm{O}$ experimento foi realizado em canteiro de propagação contendo areia como substrato, coberto com polietileno e microaspersão intermitente, com intervalos de aproximadamente duas horas (câmara de estufim), no setor da Fruticultura do Instituto Federal Goiano - Campus Ceres, de outubro a novembro de 2019. O município de Ceres está localizado na mesorregião do Centro Goiano, nas coordenadas geográficas de $15^{\circ} 18^{\prime} 28^{\prime \prime} \mathrm{S}$ e de $49^{\circ} 35^{\prime} 52^{\prime \prime} \mathrm{O}$. O clima local se caracteriza como do tipo Aw de acordo com a classificação de Köppen Geiger (quente e semiúmido), com temperatura média máxima de $26^{\circ} \mathrm{C}$. A precipitação média anual chega a $1500 \mathrm{~mm}$.

O material vegetal utilizado foi coletado de uma planta matriz localizada no município de Uruana - Goiás. Foi realizada a identificação da espécie de maracujá azedo, de acordo com Lorenzi (2006). O material foi levado do local de coleta até o preparo em uma caixa térmica com gelo, para reduzir o metabolismo das estacas e evitar perdas de água. As estacas foram cortadas com auxílio da tesoura de poda, com tamanho de $20 \mathrm{~cm}$ de comprimento, com e sem folhas, retiradas da porção intermediaria de plantas adultas. As estacas foram tratadas com AIB (ácido indolbutírico) por cinco segundos. As estacas com folhas tiveram suas folhas cortadas ao meio, diminuindo a área foliar afim de evitar maiores perdas de água e facilitar o manejo.

O delineamento utilizado foi em blocos casualizados em arranjo fatorial $2 \times 4$ (estaca com e sem folhas e quatro concentrações de AIB: 0, 1.000, 2.000 e $4.000 \mathrm{mg} \mathrm{L}^{-1}$ ), com cinco repetições e cinco estacas por unidade experimental. Realizou -se a avaliação das estacas após 40 dias, analisando as seguintes variáveis: porcentagem de estacas vivas, porcentagem de estacas enraizadas, número de brotos, porcentagem de estacas mortas e porcentagem de estacas com calos. Para a variável número de brotos, foi realizada a contagem de brotos presentes nas estacas em cada repetição. Já para as demais variáveis, foi realizada a contagem por repetição do número de estacas que apresentavam as características determinadas e realizado o cálculo de porcentagem.

Os dados obtidos foram submetidos a análise de variância (teste F), sendo as médias comparadas pelo teste de Tukey ao nível de 5\% de probabilidade e análise de regressão, utilizando o software Sisvar versão 5.7, Ferreira (2014). Nos casos em que o coeficiente de variação excedeu o limite estabelecido de $30 \%$, realizou-se a transformação dos dados para $\sqrt{x+1}$.

\section{Resultados e Discussão}

Os tratamentos nas doses de 0 e $4.000 \mathrm{mg} \mathrm{L}^{-1}$ de AIB obtiveram resultados superiores aos tratamentos com doses de 1.000 e $2.000 \mathrm{mg} \mathrm{L}^{-1}$ de AIB para a variável resposta de porcentagem de estacas vivas (Figura 1A). Segundo Araújo et al. (2011), em seu trabalho com o maracujazeiro do mato Passiflora cincinnata os melhores resultados foram obtidos quando não houve tratamento das estacas com o regulador de crescimento.

As doses de $0 \mathrm{mgL}^{-1} \mathrm{e} 4.000 \mathrm{mgL}^{-1}$ de AIB foram as que apresentaram menores resultados para estacas mortas (Figura 1B), isso se justifica pelas informações apresentadas na Figura 1A, onde as maiores porcentagens de estacas vivas foram observadas nos mesmos tratamentos. Mayer (2017) trabalhando com estacas de Passiflora caerulea constatou que menores concentrações de AIB proporcionaram maior número de estacas sobreviventes e diminuição com o aumento da concentração a partir de $1.000 \mathrm{mg} \mathrm{L}^{-1}$. 
Houve decréscimo da porcentagem de estacas enraizadas com o aumento das doses de AIB (Figura 1C). Segundo Meletti et al. (2007), em seu trabalho com enraizamento de estacas maracujazeiro doce Passiflora alata Curtis, tratadas com doses de $0,1.000,2.000$ e $3.000 \mathrm{mg} \mathrm{L}^{-1}$ de AIB, as maiores porcentagens de enraizamento foram obtidas na primavera no mês de outubro, sendo de $95,66 \%$ de estacas enraizadas. No presente trabalho as estacas foram coletadas em outubro e foram avaliadas em novembro, ainda na estação da primavera.

Segundo Sousa et al. (2014), em seu trabalho com enraizamento de estacas de maracujazeiro doce Passiflora alata com a utilização de doses de $0,1.000,2.000,3.000 \mathrm{e} 4.000 \mathrm{mg} \mathrm{L}^{-1}$ a presença de folha nas estacas favorecem o enraizamento. As estacas com um par de folhas, independentemente da concentração de AIB, apresentaram média de $61,2 \%$ de enraizamento, enquanto estacas sem folhas apresentaram média de 7,9\%.

Figura 1. (A) Estacas vivas; (B) Estacas mortas; (C) Estacas enraizadas; (D) Estacas com calo; e (E) Número de brotos por estaca de maracujá azedo sob a aplicação de diferentes concentrações de AIB. Ceres, GO. 2019.
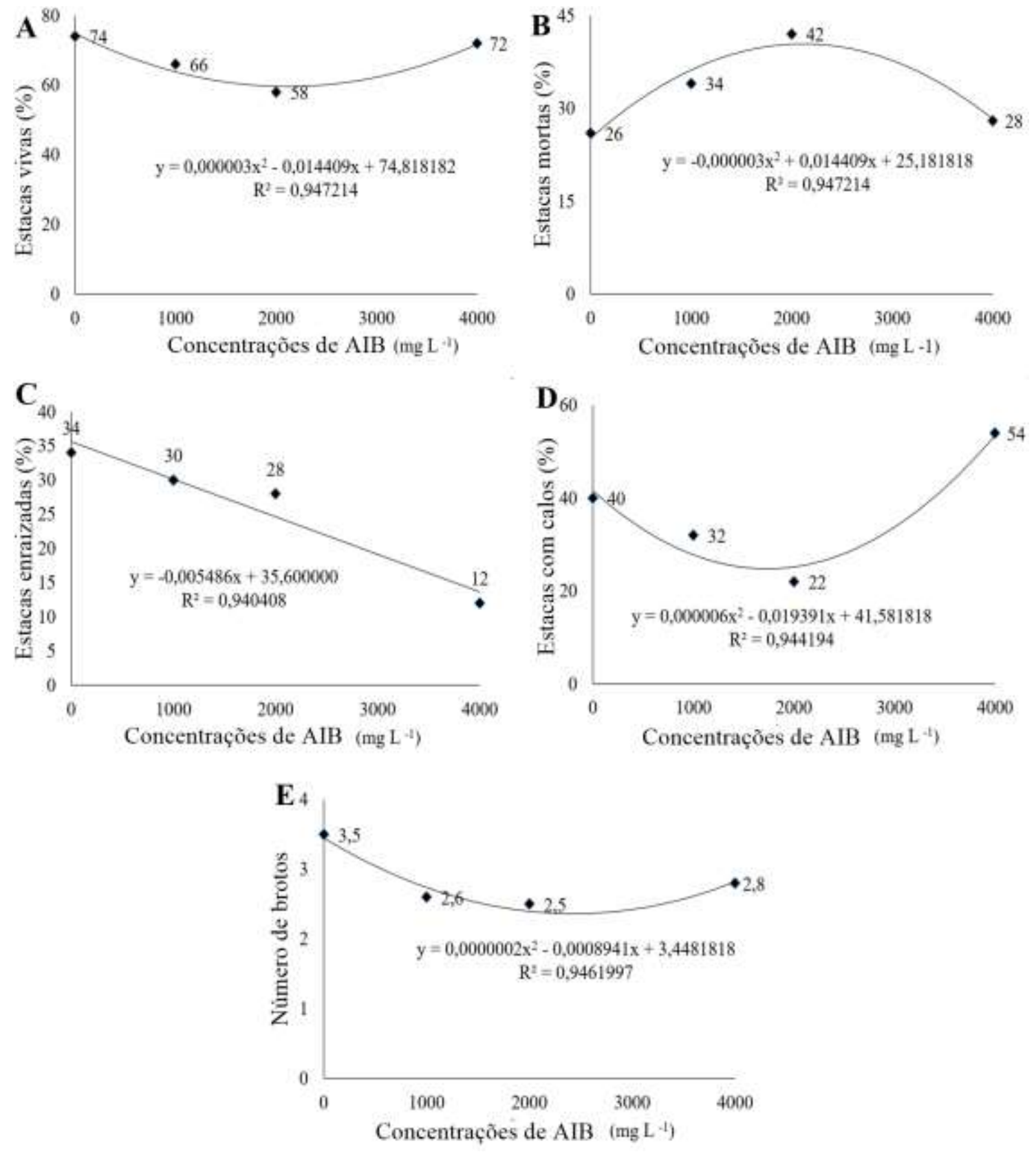

Fonte: Arquivo Pessoal (2019). 
Sabião et al. (2011), em seu trabalho com enraizamento de estacas de Passiflora nitida a porcentagem de enraizamento atingiu a média de $86,3 \%$, tendo os melhores resultados para os tratamentos com doses $1.000 ; 3.000$ e $5.000 \mathrm{mg}$ $\mathrm{L}^{-1}$, com $88,75 \%$, 95\% e 98,75\% de enraizamento, respectivamente, diferindo significativamente da testemunha $\left(0 \mathrm{mg} \mathrm{L}^{-1}\right)$, que atingiu média de 62,5\%. Segundo Vaz (2008), em seu trabalho com enraizamento de Passiflora edulis com doses de (0, 250, $500,1.000 \mathrm{ppm}$ ) de AIB, foi obtido $88 \%$ de enraizamento. Diante disso percebe-se que as estacas de maracujazeiro azedo Passiflora edulis tem melhor porcentagem de enraizamento em doses menores que $1.000 \mathrm{mg} \mathrm{L}^{-1}$.

Os tratamentos com 4.000 e $0 \mathrm{mg} \mathrm{L}^{-1}$ de AIB obtiveram as maiores porcentagens de calo nas estacas (Figura 1D). Vale et al. (2020) trabalhando com a aplicação de diferentes doses de AIB em estacas de Passiflora nitida, constataram que a maior porcentagem de estacas com calos ocorreu quando não foi aplicado o AIB. Já Silva et al (2015) concluíram que a utilização de concentrações de 1.000 e $2.000 \mathrm{mg} \mathrm{L}^{-1}$ de AIB levam a uma redução na formação de calos, e que a não aplicação de AIB promove a maior formação de calos.

$\mathrm{O}$ número de brotos foi maior com o uso da dose de $0 \mathrm{mg} \mathrm{L}^{-1}$ de AIB, apresentando resultados semelhantes entre as doses de 1.000 e 2.000 e $4.000 \mathrm{mgL}^{-1}$ de AIB (Figura 1E). As condições fisiológicas e hormonais dos explantes utilizados, aliada às concentrações de reguladores de crescimento, devem proporcionar um equilíbrio adequado entre citocininas e auxinas, para promover maior formação de brotos (Ferreira et al, 2020). Partindo desse pressuposto indicado, a aplicação de AIB pode gerar um desbalanço nesta relação auxina/citocinina, diminuindo assim a produção de brotos em comparação ao tratamento controle.

As estacas com folha apresentaram média de $86 \%$ de estacas vivas, sendo diferente estatisticamente das estacas sem folha que obtiveram média de 49\% (Tabela 1). Segundo Meletti (2007), a superioridade das estacas dotadas de folhas reduzidas à metade pode estar relacionada à menor brotação das estacas no leito de enraizamento, em comparação às estacas sem folhas, que apresentam emissão de brotações precocemente.

Tabela 1. Estacas vivas (EV), estacas mortas (EM), estacas enraizadas (ER), estacas com calos (EC) e número de brotos (NB), sob tipos de estaca com e sem folhas. Ceres, GO. 2019.

\begin{tabular}{cccccc}
\hline Tipo de estaca & EV $(\%)$ & EM $(\%)$ & ER $(\%)$ & EC $(\%)$ & NB \\
\hline Com folha & $86 \mathrm{a}$ & $14 \mathrm{~b}$ & $39 \mathrm{a}$ & $41 \mathrm{a}$ & $3,6 \mathrm{a}$ \\
Sem folha & $49 \mathrm{~b}$ & $51 \mathrm{a}$ & $16 \mathrm{~b}$ & $33 \mathrm{a}$ & $2,1 \mathrm{~b}$ \\
\hline CV $(\%)$ & 27,12 & 36,49 & 34,02 & 42,59 & 31,90 \\
\hline
\end{tabular}

Médias seguidas por letras distintas na coluna diferem entre si pelo teste de Tukey a 5\% de probabilidade. Fonte: Autores.

A interação entre os tipos de estacas foi significativa, dessa forma estacas com e sem folha diferiram estatisticamente. As estacas com folhas tiveram menor porcentagem de estacas mortas em relação as estacas sem folhas (Tabela 1). O resultado foi de 3,5 vezes das estacas sem folhas para as com folhas. Segundo Vaz (2008) em seu trabalho com enraizamento de estacas de Passiflora edulis, obteve-se $12 \%$ de estacas mortas. No presente trabalho obteve-se maior porcentagem de estacas mortas com a aplicação de maiores doses de AIB (Figura 1B).

As estacas com folhas proporcionaram maior porcentagem de estacas enraizadas e número de brotos em comparação com as estacas sem folhas (Tabela 1). A presença de folhas nas estacas permite a produção de carboidratos assim como de complexos responsáveis pelo enraizamento, possibilitando a sobrevivência das estacas por um maior período de tempo, consequentemente, este maior período de sobrevivência possibilita a manifestação de respostas aos estímulos endógenos e exógenos das moléculas de auxinas (Silva et al, 2015). O desenvolvimento de um sistema de enraizamento mais eficiente resulta em mudas com maior qualidade fisiológica e diminuição de perdas durante a fase de aclimatização (Damiani \& Schuch, 
2009; Oliveira et al., 2020).

Não houve diferença significativa para a formação de calos entre as estacas com folhas e sem folhas (Tabela 1). Souza et al. (2014) observaram em seu trabalho com estacas de maracujazeiro doce Passiflora alata que com a utilização de doses de 0, 1.000, 2.000, 3.000 e $4.000 \mathrm{mg} \mathrm{L}^{-1}$ a formação de calo predominou em $55 \%$ nas estacas com folhas, enquanto nas estacas sem folhas houve apenas $5 \%$ de formação de calo. No presente trabalho a maior dose de AIB $\left(4.000 \mathrm{mg} \mathrm{L}^{-1}\right)$ proporcionou maior porcentagem de calos (Figura 1D), e consequentemente, maior porcentagem de estacas vivas, juntamente, com a dose Zero. Ou seja, maior ou menor concentração de AIB pode proporcionar maior porcentagem de calos e de estacas vivas independentemente se possui ou não folhas.

As estacas com folhas proporcionaram maior resultado e foram diferentes estatisticamente das estacas sem folhas para o número de brotos (Tabela 1). Isso pode ser explicado pela quantidade de fotoassimilados nas estacas com folhas ser maior que nas estacas sem folhas. Conforme Braga et al. (2006) é de grande interesse a obtenção de estacas enraizadas com brotos, o que representa uma estaca que completou a formação da muda. A manutenção de folhas nas estacas pode favorecer a produção de mudas por estacas de caule, pois, possibilita a produção de carboidratos assim como de moléculas com ação hormonal que ocorrem principalmente nas folhas (Silva et al., 2015).

\section{Considerações Finais}

Houve decréscimo da porcentagem de estacas enraizadas com o aumento das doses de AIB. O aumento das doses de AIB até a dose de $2.000 \mathrm{mg} \mathrm{L}^{-1}$ proporcionou maior porcentagem de estacas mortas de maracujá azedo. A presença de folhas nas estacas produziu maior porcentagem de estacas vivas, enraizadas, com calos e brotos e as estacas sem folhas produziram maior quantidade de estacas mortas. O tratamento mais indicado é a não aplicação de AIB e a utilização de estacas com folhas.

\section{Referências}

Araújo, F. P., Mouco, M. A. do C., Ono, E. O., \& Rodrigues, J. D. (2011). Substratos e concentrações de ácido indolibutírico no enraizamento de estacas de Passiflora cincinnata Mast. Magistra, Cruz das Almas - BA, 22(1), 21-27.

Bernardo, B. E. C., Sato, A. J., \& Zonetti, P. C. (2020). Propagação por estaquia de erva-baleeira (Cordia verbenacea DC.). Revista em Agronegócio e Meio Ambiente, [S.L.], 13(3), 947-957.

Braga, M. F., Santos, E. C., Junqueira, N. T. V., Sousa, A. A. T. C., Faleiro, F. G., Rezende, L. N., \& Junqueira, K. P. (2006). Enraizamento de estacas de três espécies silvestres de Passiflora. Revista Brasileira de Fruticultura, Jaboticabal - SP, 28(2), 284-288.

Damiani, C. R., \& Schuch, M. W. (2009). Diferentes substratos e ambientes no enraizamento in vitro de mirtilo. Ciência Rural, Santa Maria, 39(2), 563-566.

Empresa Brasileira de Pesquisa Agropecuária - Embrapa. (2020). Produção brasileira de maracujá em 2019. Brasília: Embrapa. http://www.cnpmf.embrapa.br/Base_de_Dados/index_pdf/dados/brasil/maracuja/b1_maracuja.pdf.

Ferreira, D. F. 2014. Sisvar. Versão 5.6. Lavras: UFLA/DEX. <http://www.dex.ufla.br/ danielff/en/softwares/sisvar_en.html>.

Ferreira, L. V., Taniguchi, M., Barreto, C. F., Silva, T. B., Antunes, L. E. C., \& Dutra, L. F. (2020). Indução de brotos in vitro em maracujazeiro doce BRS Mel do Cerrado. Brazilian Journal Of Development, 6(3), 9644-9652.

Hartmann, H. T., Kester, D. E., Junior Davies, F. T., \& Geneve, R. L. (2011). Plant propagation: principles and practices. 8th. ed. New Jersey: Englewood Clipps. 900 p.

Junghans, T. G., Jesus, O. N., Girardi, E. A., \& Faleiro, F. G. (2016). Sementes e Mudas: O que é a estaquia do maracujazeiro. In: FALEIRO et al., Maracujá: O produtor pergunta, a Embrapa responde. Brasília DF: Embrapa Cerrados, Cap. 4, 41-54.

Lima Neto, M. C., Ribeiro, J. S., \& Bezerra Neto, E. (2009). Enraizamento de estacas de bambu com o uso de auxinas. Revista Acadêmica Ciência Animal, Curitiba, 7(2), 175-179.

Lorenzi, H., Bacher, L., Lacerda, M., \& Sartori, S. (2006). Frutas Brasileiras e exóticas cultivadas (de consumo in natura). Instituto Plantarum de Estudos da Flora. 672p.

Mayer, L., Meneghini, J., Fior, C. S., \& Freitas, E. M. (2017). Propagação de Passiflora caerulea L. por estaquia. Iheringia, Série Botânica, 72(1), 5-8.

Meletti, L. M. M., Barbosa, W., Pio, R., Sant'anna Tucci, M. L., Costa, A. A., \& Pires Feldberg, L. (2007). Influência da estação do ano, da presença de folhas e do ácido indolbutírico no enraizamento de estacas de maracujazeiro-doce (Passiflora alata Curtis). Revista UDO Agrícola, 7(1), 68-73. 
Research, Society and Development, v. 10, n. 3, e23810313209, 2021

(CC BY 4.0) | ISSN 2525-3409 | DOI: http://dx.doi.org/10.33448/rsd-v10i3.13209

Meletti, L. M. M. (2011). Advances in passionfruit culture in Brazil. Revista Brasileira de Fruticultura, Jaboticabal, 33(1), 83-91.

Meletti, L. M. M., Furlani, P. R., Álvares, V., Soares-Scott, M. D., Bernacci, L. C., \& Azevedo Filho, J. A. (2002). Novas Tecnologias Melhoram a Produção de Maracujá. O Agronômico, 54(1), 30-33.

Oliveira, B. A. S., Maciejewski, P., Ramm, A., Frölech, D. B., Mattos, M. G., Gris, T., Assis, A. M., \& Schuch, M. W. (2020). Tipos e concentrações de auxinas no enraizamento ex vitro de mirtileiro 'Woodard'. Brazilian Journal Of Development, 6(6), 37823-37832.

Sabião, R. R., Silva, A. C. C., Martins, A. B. G., \& Cardoso, E. R. (2011). Enraizamento de estacas de Passiflora nitida submetidas a diferentes concentrações de ácido indolbutírico (AIB). Revista Brasileira de Fruticultura, 33(1), 654-657.

Santos, J. L., Matsumoto, S. N., D'arêde, L. O., Luz, I. S., \& Viana, A. E. S. (2012). Propagação vegetativa de estacas de Passiflora cincinnata mast. em diferentes recipientes e substratos comerciais. Revista Brasileira de Fruticultura, Jaboticabal - SP, 34(2), 581-588.

São José, A. R., \& Pires, M. M. (2011). Maracujá: Avanços Tecnológicos e Sustentabilidade: Aspectos Gerais da Cultura do Maracujá no Brasil. <http://www.uesc.br/editora/livrosdigitais2016/maracuja_avancos_tecnologicos_sustentabilidade.pdf>.

Silva, A. S., Reges, N. P. R., Melo, J. K., Santos, M. P., \& Sousa, C. M. (2015). Enraizamento de estacas caulinares de ixora. Ornamental Horticulture. 21(2), 201-208.

Sousa, C. M., Carvalho, B. M., \& Santos, M. P. (2014). Enraizamento de estacas de maracujazeiro-doce (Passiflora alata Curtis). Científica, $42(1) .68-73$.

Vale, L. S. R., Pires, R. R., Marques, M. L. S., Rios, A. D. F., \& Cruz, D. R. C. (2020). Ácido indolbutírico no enraizamento de estacas de maracujazeiro do Cerrado. Brazilian Journal of Development, 6(7), 50920-50928.

Vaz, C. F. (2008). Enraizamento de Estacas Herbáceas de Passifloras Silvestres e Sua Utilização como Porta-enxertos de Maracujazeiro Azedo. <https://repositorio.unb.br/bitstream/10482/5028/1/2008_CarolinadeFariaVaz.pdf>. 